\title{
INCORPORATING SPECTRAL INDICES AND TEXTURAL FEATURES FOR IMPROVED CLASSIFICATION ACCURACY TOWARDS SEMI-AUTOMATED RIVER SAND MAPPING USING HIGH-RESOLUTION MULTISPECTRAL SATELLITE IMAGERY
}

\author{
Virat Arora ${ }^{1,2}$, S. S. Rao ${ }^{1}$, E. Amminedu ${ }^{2}$ and P. Jagadeeswara Rao ${ }^{2}$ \\ ${ }^{1}$ National Remote Sensing Centre, Hyderabad, India \\ ${ }^{2}$ Dept. of Geo-Engineering, Andhra University College of Engineering, Visakhapatnam, India \\ Email: aroravirat@gmail.com
}

\begin{abstract}
For the ephemeral river channels in semi-arid regions of India, after every Monsoon season, prompt preparation of river sand distribution maps is often necessary for river sand auditing before resuming the sand mining operations. The process can be readily assisted by classifying the satellite-based remotely sensed imagery, although often confronted by limited accuracy levels arising due to poor distinguishing capability among the spectrally similar classcategories. This study aims to improve the classification accuracy targeting river sand deposits by systematically examining the effects of including spectral indices and textural features in the feature-space while classification. Two most common classification algorithms, viz. Maximum Likelihood Classification (MLC) and Support Vector Machine (SVM) classification were used. The results show that SVM performed even better when Normalized Difference Vegetation Index (NDVI) and correlation texture feature computed at $3 \times 3$ window size were included in the feature-space comprising original spectral bands.
\end{abstract}

Key words: River Sand, MLC, SVM, Spectral Indices, Textural Features

\section{Introduction}

River sand is a valuable natural resource with its major utilization in the construction industry. With the increasing pressure of rapid infrastructural development, there has been an equivalent rise in the market demand of river sand. Consequently, the limited sources of river sand are placed with an undue strain in terms of disturbed riverine environment. To ensure the sustainable use of river sand, regular audits of their reserves are often recommended by the policy makers. Preparation of river sand distribution maps is an important step in river sand audits. Regular updating of such maps requires frequent cumbersome field surveying spells that usually encompasses involvement of multiple stakeholders. In this scenario, often, old data are relied upon and are carried forward year-by-year without updating due to lack of availability of resources, and more importantly, due to lack of knowledge of appropriate technique (Mitra and Singh, 2015). Remote sensing data has demonstrated potential in the applications involving generation of planimetric maps depicting river sand deposits. For example, Ramkumar et al. (2015) made an attempt to identify the active-channel sand bars within Kaveri River through visual interpretation from IRS 1B LISS-III imagery of the year 2008, compared it with Survey of India toposheet of the year 1971, and found the areal extent of these sand bars to be increasing at a rate of $1.05 \mathrm{~km}^{2}$ per year (Ramkumar et al., 2015).

For eliminating the problem of biasedness in image interpretation, and towards introducing automation, numerous classification algorithms have been developed by the research community such as pixel-based, object-based and knowledge-based classification algorithms that use spectral, spatial or temporal information, or any combination of these, via unsupervised clustering methods or supervised learning methods (Lu and Weng, 2007). For example, Leckie et al. ${ }^{(2005)}$ performed pixel-based image classification on $0.8 \mathrm{~m}$ spatial resolution aerial imagery dataset with eight spectral bands for mapping of stream features such as deep, moderate and shallow classes of water along with sand, gravel, cobble, and rocky areas. Feature-space optimization is a critical step towards increasing the classification accuracy. Features such as spectral signatures, vegetation indices, textural and terrain features are some of the possible variables in any classification process (Lu and Weng, 2007). The key is to improve the class-separability by incorporating the distinguishing characteristics among the land cover classes present in the study area. Various spectral indices, when included in the 
feature-space, have contributed towards improving the overall accuracy of classification (Zha et al., 2003). Normalized Difference Vegetation Index (NDVI), developed by Rouse et al. (1973) is one of the commonly used indices. Also, Normalized Difference Water Index (NDWI) is specifically used to enhance the surface water features and works as a complementary index along with NDVI (Zha et al., 2003). By using NDWI, estimation of turbidity in water may be performed (McFeeters, 1996). To enhance the separation of completely bare, sparse and dense vegetation cover, Bare Soil Index (BSI) is used (Azizi et al., 2008).

Further, incorporating image texture properties for improved classification accuracy has been suggested by many studies like Haralick et al. (1973) and Huang et al. (2014). Image texture is a measure that depicts spatial arrangement of the pixel grey levels (Carbonneau et al., 2005). Although there are several measures available to harness textural properties from image data (Chaurasia and Garg, 2013), but Grey Level Co-occurrence Matrix (GLCM) is one of the widely utilized methods in case of satellite imagery (Haralick et al., 1973; Huang et al., 2014; Li et al., 2011). However, it is important to consider about the choice of texture feature and window size to adopt for the study (Pathak and Dikshit, 2010). The present study attempts to make an assessment on the hypothesis that for the spatial mapping of river sand, spectral indices and textural features improve the accuracy of supervised classification on the multispectral satellite imagery. Various combinations of features were prepared and each of the combinations was examined using two most prevailing supervised classification methods, namely, Maximum Likelihood Classification (MLC) and Support Vector Machine (SVM). MLC is a parametric classification method wherein it is assumed that the land cover features are normally distributed and hence, to derive the statistics, a sufficiently large number of training samples are required for MLC (Richards and Jia, 1999). Whereas, SVM, which has sharply gained popularity in remote sensing (Mountrakis et al., 2011), is a non-parametric machine learning algorithm where parameters such as mean vector and covariance matrix are not used, and hence, any kind of assumption about the data is not required (Lu and Weng, 2007). The reader is referred to Lu and Weng (2007) for a detailed description of various remote sensing image classification methods.

\section{Study Area}

A rectangular extent (bottom-left coordinates: $72^{\circ} 32^{\prime} 13.484^{\prime \prime} \mathrm{E} 2^{\circ} 46^{\prime} 57.250^{\prime \prime} \mathrm{N}$; top-right coordinates: $72^{\circ} 36^{\prime} 29.242^{\prime \prime} \mathrm{E} 2^{\circ} 49^{\prime} 23.828^{\prime \prime} \mathrm{N}$ ) of area 3157.5 ha comprising part of Luni River near Samdari town of Barmer District in Rajasthan was selected as the study area (Figure 1). The area was identified keeping in view the presence of maximum possible number of land cover classes representing the semi-arid climatic region so as to test the distinguishing ability of the image-processing classifiers and the feature-spaces being used in the study.

Figure 1: False Colour Composite of Planet Labs Data (3 M Spatial Resolution)
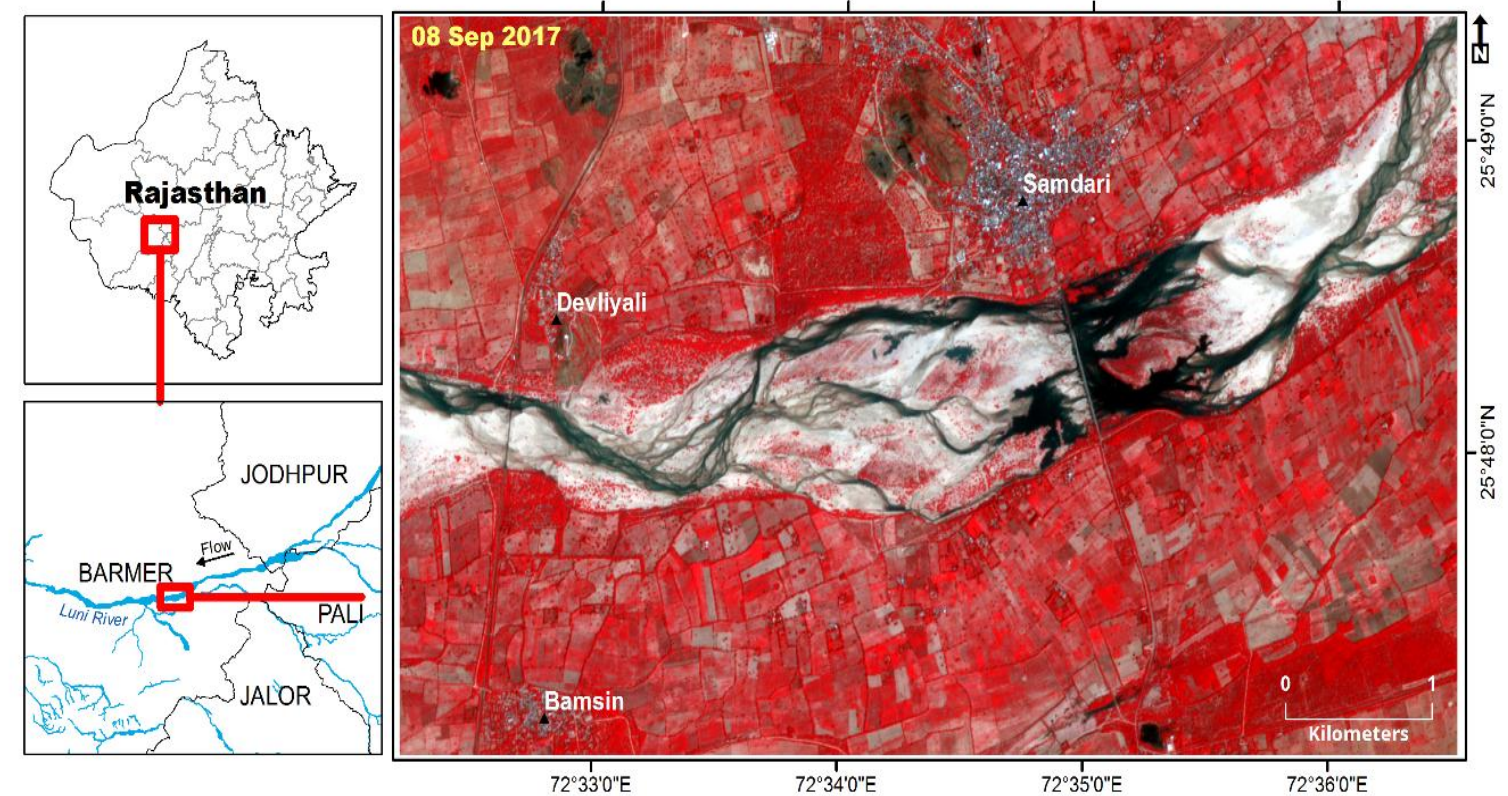


\section{Dataset Used}

A four-band (blue, green, red and near-infrared wavelength regions) multi-spectral imagery (date of pass: 08 September 2017) acquired by the Planet Scope constellation of dove satellites (Planet Team, 2017) was utilized for the present study (Figure 1). The access to the imagery-dataset was granted for academic research under Planet's Education and Research program. The data, in WGS 1984 spatial reference system and UTM Zone-43 projection, was supplied with geometric corrections \& orthorectification pre-applied. Cubic Convolution resampling method was adopted while projecting the imagery. The resampled pixel size for the imagery was $3 \mathrm{~m}$. Pixel digital number (DN), in 16-bit radiometric resolution, was surface reflectance value incorporated with the scaling factor of 10000 . Field visit in the study area was conducted during the month of September 2017 (Figure 2) although limitations were enforced by the local police due the widespread threat of sand mafia subsequent to the ban imposed by the Hon'ble High Court of Rajasthan. Finer spatial resolution imagery of a similar date sourced from Google Earth was primarily referred during the research work.

Figure 2: (a) Vegetation present on inactive portions of river sand deposits; (b) Class boundary of coarse-grained and fine-grained river sand cover as pictured during the field visit

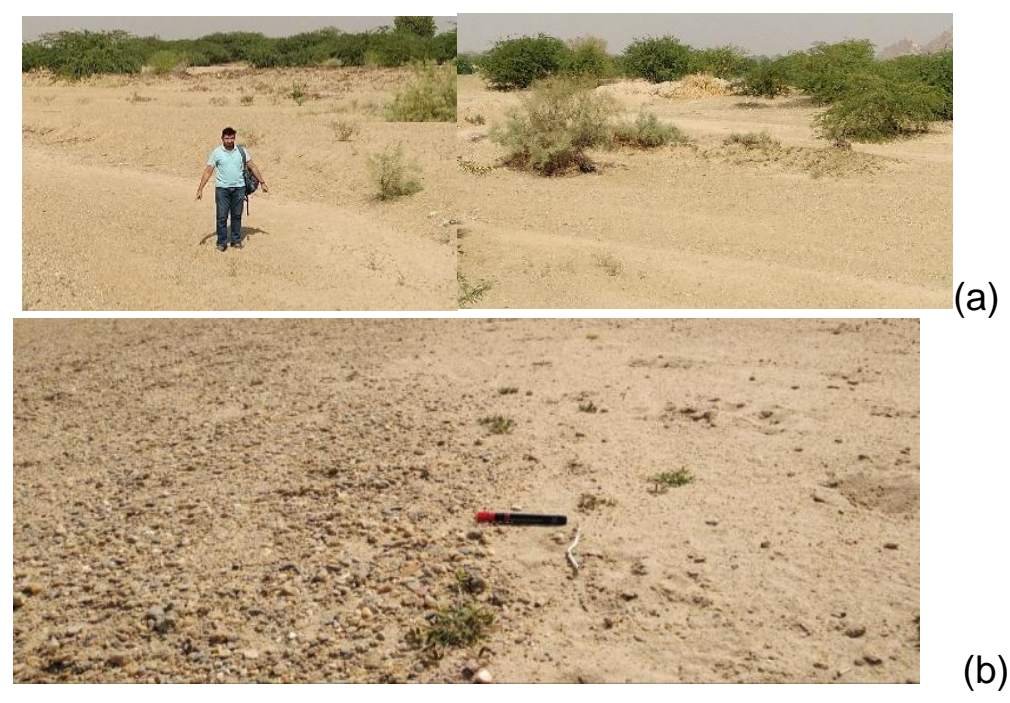

\section{Methodology}

Varying input feature-spaces were tested for classification accuracy using two image classification methods viz. MLC and SVM targeting riverine sand mapping. The process included derivation of spectral indices and textural features that were used to construct the feature-spaces. Subsequently, classification steps were performed repeatedly and resultant accuracies were analyzed to find the best suited method for river sand mapping. The detailed steps are listed below (as also graphically illustrated in Figure 03): For identifying the possible number of land cover types present, initially, a visual interpretation was performed over the false color composite of the study area. Additionally, spectral clustering was performed using ISO Cluster Tool in ArcGIS 10.6.1 which was programmed to generate 100 clusters initially, that were later grouped to form 10 meaningful classes. In this manner, a classification scheme was designed while focusing on the riverine environment (Table 01). Training sample areas for each class were delineated with the help of field knowledge and the higher resolution imagery of a similar date as available from Google Earth. Samples were improved by testing them for purity and separability by means of a preliminary Maximum Likelihood Classification using the spectral bands. Once finalized, the same set of sample areas was used in the subsequent part of the experiment.

Spectral indices (NDVI, NDWI and BSI) were generated from the input multi-band imagery using Raster Calculator tool in ArcGIS 10.6.1.

$N D V I=(N I R-R e d) /(N I R+R e d)$

$N D W I=($ Green $-N I R) /($ Green $+N I R)$

$B S I=[(N I R+$ Green $)-$ Red $] /[($ NIR + Green $)+$ Red $]$

For incorporating textural information, second-order texture filters were applied on the grey-level co-occurrence matrix (GLCM) using ENVI 5.4. The filters included mean, variance, homogeneity, contrast, dissimilarity, entropy, second moment and correlation. Greyscale 
quantization level was set to 8-bits in order to reduce the processing time. Four sets of varying window sizes $(3 \times 3,5 \times 5,7 \times 7$ and $9 \times 9)$ were prepared, each set comprising the above mentioned eight filters.

Various combinations of the spectral bands, spectral indices and/or textural features were prepared using Composite Bands Tool as available in ArcGIS 10.6.1.

Every combination was tested for the performance by MLC and SVM classifiers as available in ArcGIS 10.6.1. For a given feature-space, first, the classifier was trained using the sample areas. The trained classifier was then applied to the imagery of given feature-space covering the full study area. For executing the repeated steps, routines were created using the ArcGIS Model Builder.

For the accuracy assessment, testing sample areas were delineated avoiding the locations of training sample areas. For this, a manual classification of the same image was performed at the mapping scale of 1:10000 using image interpretation techniques supported by the ground truth evidence as collected by the field visits and information from Survey of India Topographic Maps, Bhuvan Geo-portal of National Remote Sensing Centre (Indian Space Research Organisation) as well as the similar date higher resolution imagery as available from the Google Earth platform.

Sample points for testing were generated adopting the Stratified Random Sampling strategy on the manually classified image. The sample points were randomly distributed within each class, the number of points in each class being proportionate to the relative area of the classes. In all, 512 points were generated by using Create Accuracy Assessment Points tool in ArcGIS 10.6.1. The same set of test sample points was used in the accuracy assessment of all the classified outputs generated in step 6. Confusion matrix was generated for each of the classification output.

Figure 03: Flowchart of the Methodology followed

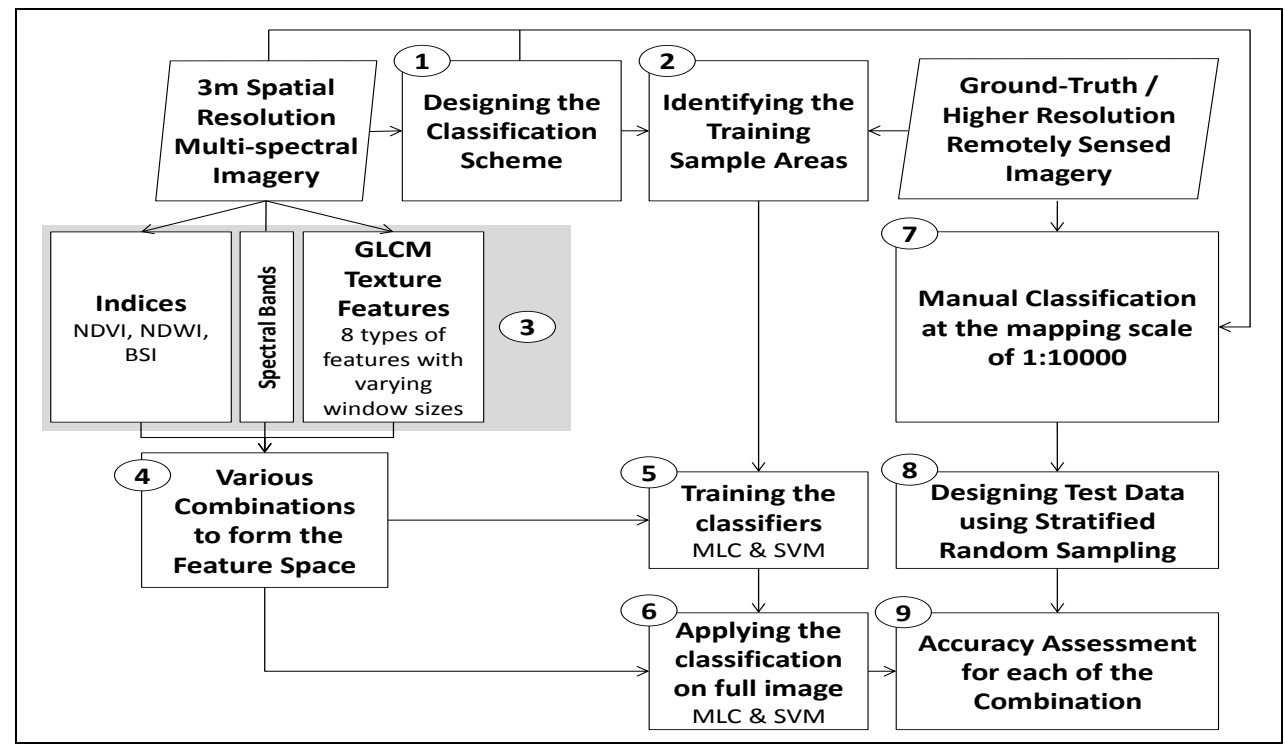

Table 01: Classification Scheme Adopted for the Present Study

\begin{tabular}{|l|l|l|}
\hline \multicolumn{2}{|l|}{ Class } & Description \\
\hline 1 & Built-Up & Residential buildings including transportation roads \\
\hline 2 & Dense-Vegetation & Trees, bushes and standing healthy agricultural crops \\
\hline 3 & Sparse-Vegetation & Pasture-lands / grasslands / sparse vegetation cover \\
\hline 4 & Bare-Soil & Land devoid of vegetation and any other inhabitation; includes fallow land \\
\hline 5 & Rocky-Area & Barren rocky; includes open pit rock mining areas present in the study area \\
\hline 6 & Non-Turbid-Water & Water exhibiting darker tone \\
\hline 7 & Turbid-Water & Water exhibiting lighter tone due to mixed reflectance from sand bed material \\
\hline 8 & Wet-River-Sand & River sand saturated by water \\
\hline 9 & Coarse-River-Sand & Sand deposits within river channel with less bright / grey tones \\
\hline 10 & Fine-River-Sand & Sand deposits within river channel with brighter tones \\
\hline
\end{tabular}




\section{Results and Discussion}

The Kappa values derived from confusion matrices of the classification outputs were graphically analyzed to study the effect of varying the feature-space during classification. The results are grouped into three sets of effects, depending upon the additions to the featurespace:

\section{Effect of Adding Spectral Indices to the Feature-Space}

In the first set, Kappa values were assimilated for cases when only spectral indices viz. NDVI, NDWI and BSI were added to the composite of original spectral bands as shown in Figure 04. With SVM, better results were achieved when NDVI was included with the spectral features. No improvement was seen when NDWI was also added to this composite. Whereas, BSI adversely affected the results whenever included in the feature-space. In the case of MLC, no improvements were seen with the inclusion of any of the spectral indices in the feature-space.

Figure 04: Comparison of Accuracies of Classification Using Various Indices along with Spectral Features

\begin{tabular}{|r|r|r|r|r|r|r|r|}
\hline \multicolumn{7}{|c|}{ Kappa Accuracy } \\
Spectral \\
Spectral + NDVI
\end{tabular}

\section{Effect of Adding Textural Features to the Feature-Space}

Kappa values were compared to study the impact of varying window sizes while preparing the GLCM-based textural features which were added to the original spectral bands with the sequence shown in Figure 05. It was observed that SVM classification accuracy decreased when opting for bigger window sizes while generating texture features. Whereas for MLC, a significant decrement was observed when any of the texture features were added to the feature-space. Seeing the results, it was decided to focus on $3 \times 3$ window size among all GLCM variants in rest of the study. Further, as shown in Figure 06, all the texture features generated with $3 \times 3$ window size were added one at a time to the spectral features and classified using the two classifiers. It was observed that with SVM, correlation feature produced best results followed by mean and variance. Whereas with MLC, no improvement was seen in Kappa values, in fact, variance features performed worst.

\section{Figure 05: Comparison of Accuracies of Classification for the Case when GLCM-Based Textural Features Derived at Various Window Sizes was added to Original Spectral Features}

\begin{tabular}{|c|c|c|c|c|c|c|}
\hline \multicolumn{7}{|c|}{ Kappa Accuracy } \\
\hline & 0.40 & 0.50 & 0.60 & 0.70 & 0.80 & \\
\hline \multicolumn{7}{|l|}{ Spectral } \\
\hline Spectral + GLCM $3 \times 3$ & & & & & & $\square \mathrm{MLC}$ \\
\hline Spectral + GLCM 5×5 & & & & & & - SVM \\
\hline Spectral + GLCM 7x7 & & & & & & \\
\hline Spectral + GLCM 9x9 & & & & & & \\
\hline
\end{tabular}

\section{Effect of Adding Both Spectral Indices and Textural Features to the Feature-Space}

Having observed from Figure 06 that with SVM, correlation texture feature at $3 \times 3$ window size performed best among all the texture features, this feature was added to the multispectral bands along with various combinations of spectral indices in the composite. The results are shown in Figure 07. It is evident from the figure that with SVM, "Spectral + Correlation + NDVI" performed best among all other feature-spaces with Kappa value of 0.794 (Figure 08). BSI was again proved to give a decreased accuracy whenever included in the composite. Again, MLC was found to show no significant improvements with the added features in feature-space. 
Figure 06: Comparing Accuracies of Classification Using Various GLCM-Based Features Derived at 3×3 Window Size Along with Spectral Features

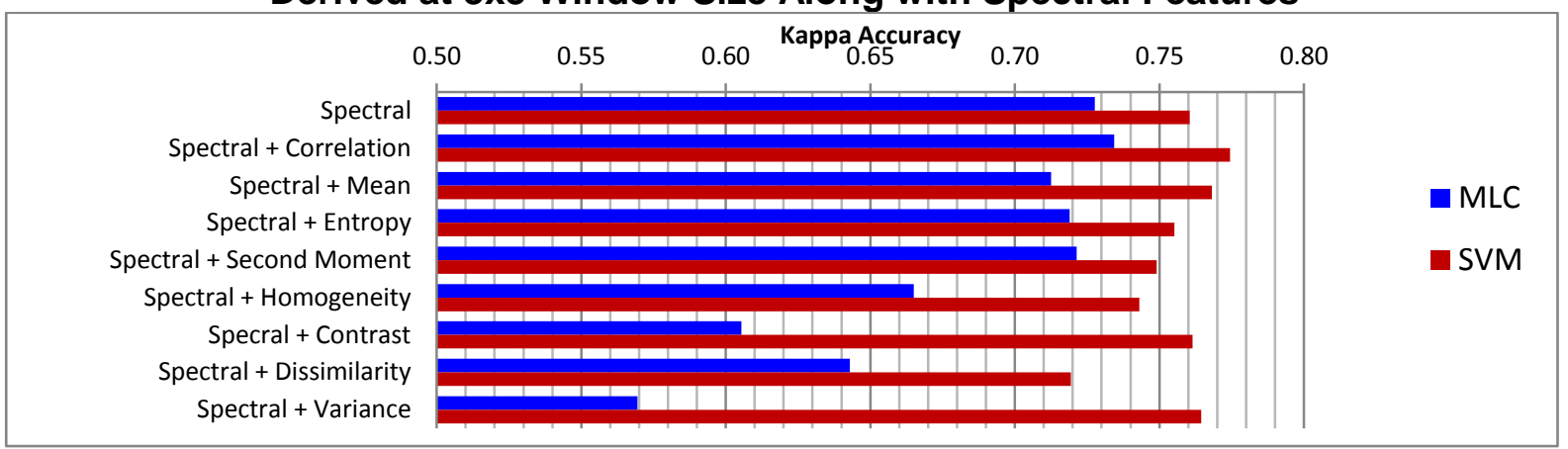

Figure 07: Comparing Accuracies of Classification Using Various GLCM-Based Features Derived at $3 \times 3$ Window Size and Various Indices Along with Spectral Features

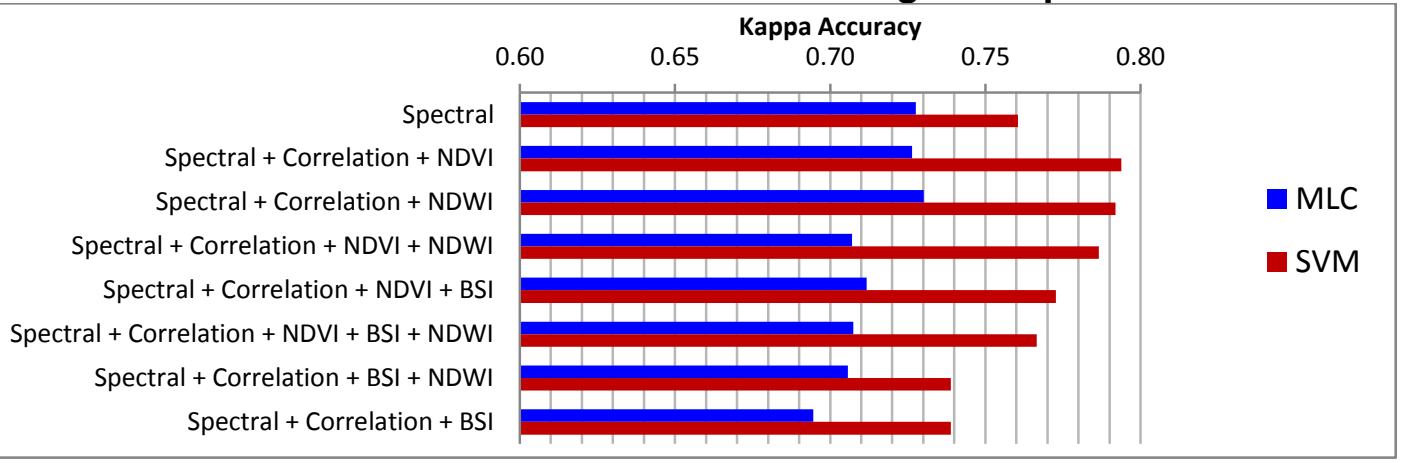

Figure 08: SVM Classification Output that Achieved the Highest Kappa Accuracy (0.794) During the Study - Generated by Adding NDVI and Correlation Texture Feature with 3x3 Window size To the Composite of Spectral Bands

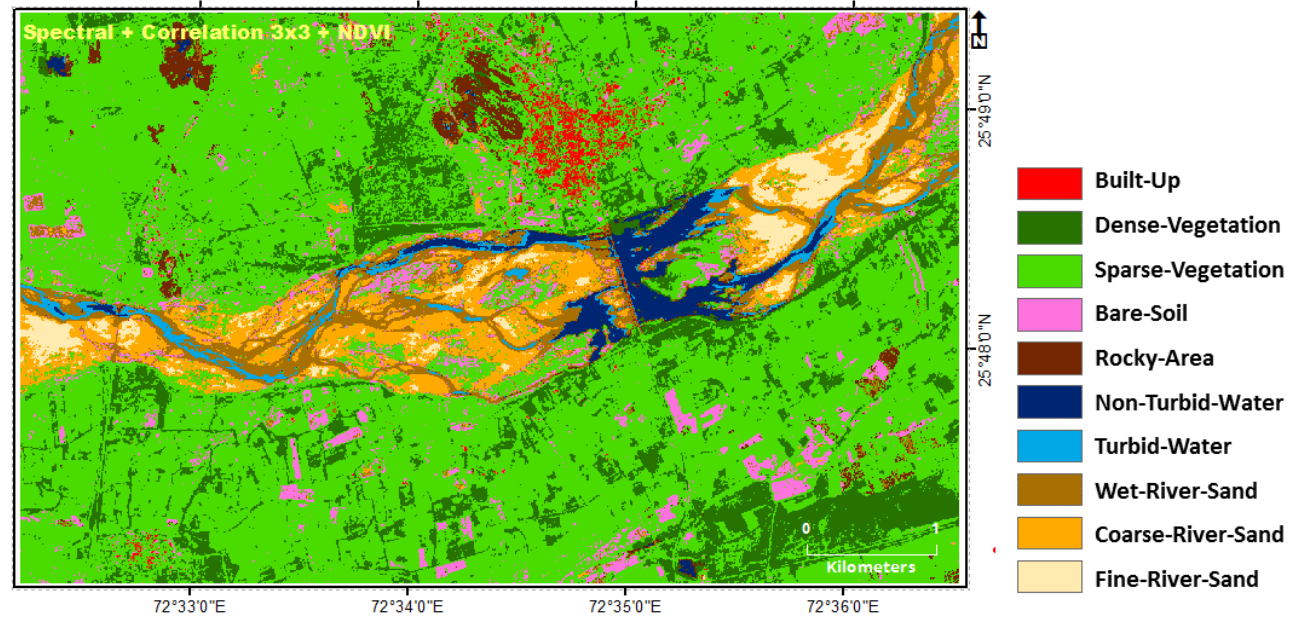

To evaluate the class-wise performance with varying feature-spaces, user's and producer's accuracies of each class were plotted (as shown in Figure 09) from the best classification results as examined from the three cases described above. For a classification to be satisfactory, it is desirable for any class plot to tend towards the top right corner of the graphs shown in Figure 09. Overall, relatively better performing classes were Fine-River-Sand, Coarse-River-Sand, Turbid-Water, Non-Turbid-Water, Sparse-Vegetation and DenseVegetation wherein both user's and producer's accuracies were found to be towards the higher side for both SVM and MLC. Classes for which a notable amount of misclassification (omission/commission errors) was detected were Wet-River-Sand, Rocky-Area, Bare-Soil and Built-Up. This was due to the spectral confusion occurring in case of channel sand bars with urban classes and bare soil found outside the channel (Gilvear et al., 2004). Spectral confusion also arise by the development of vegetation over the inactive bars that can influence the optical properties of channel bar, although no or sparse vegetation cover indicates an active channel bar (Hooke and Yorke, 2011; Wang et al., 2016). However, Wet-River-Sand, Rocky-Area, BareSoil and Built-Up were found to be better classified by SVM when compared with MLC. It was 
observed that SVM with "Spectral + Correlation + NDVI" outperformed in the whole experiment because these classes were classified with improved accuracies.

Figure 09: Class-Wise Representation of User's and Producer's Accuracies from Various Feature-Space Combinations
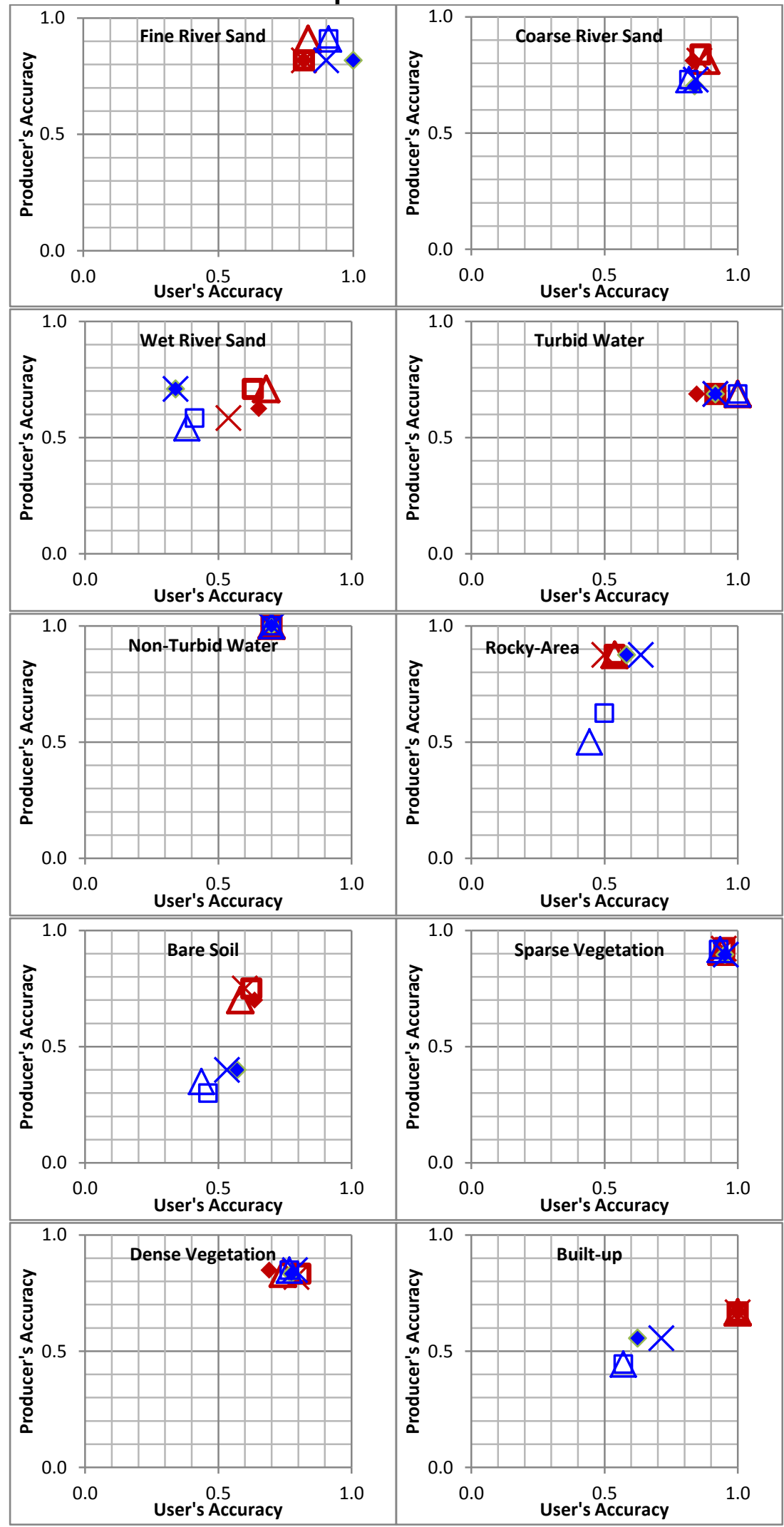

$\checkmark$ mlc Spectral

$\triangle$ mlc Spectral + NDVI

$\times$ mlc Spectral + Correlation

$\square$ mlc Spectral + Correlation + NDVI

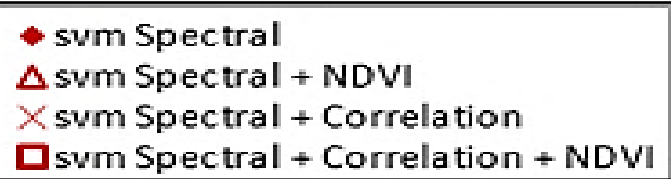




\section{Conclusion}

In this study, pixel-based semi-automated mapping of river sand was attempted by the means of space-based remotely sensed imagery. The study showed that with the increasing availability of high-spatial-resolution multispectral data, river sand planimetric extent can be readily mapped by applying supervised image classification techniques like MLC and SVM, SVM performing better among them. Moreover, accuracy of SVM classifier increases when NDVI and correlation texture feature computed at $3 \times 3$ window size are added to the composite of spectral bands while classification. The resultant planimetric spread of Fine-River-Sand, Coarse-River-Sand and Wet-River-Sand in the study area was $67.3 \mathrm{ha}, 209.5 \mathrm{ha}$ and $189.9 \mathrm{ha}$, respectively calculated with kappa value of 0.794 . Challenge still lies in distinguishing WetRiver-Sand from Bare-Soil and Built-Up class categories, for which, it is suggested to include contextual information in addition to the spectral and textural features.

\section{References}

1. Azizi, Z., Najafi, A., Sohrabi, H. (2008) Forest Canopy Density Estimating, Using Satellite Images. Int. Arch. Photogramm. Remote Sens. Spat. Inf. Sci. - ISPRS Arch. 4. doi:10.

2. Carbonneau, P.E., Bergeron, N.E., Lane, S.N. (2005) Texture-based image segmentation applied to the quantification of superficial sand in salmonid river gravels. Earth Surf. Process. Landforms 30, 121-127. doi:10.1002/esp. 1140

3. Chaurasia, K., Garg, P.K. (2013) A Brief Review on Texture Analysis Methods. Stud. Surv. Mapp. Sci. 1, 28-36.

4. Gilvear, D.J., Davids, C., Tyler, A.N. (2004) The use of remotely sensed data to detect channel hydromorphology: River Tummel, Scotland. River Res. Appl. 20, 795-811.

5. Haralick, R.M., Shanmugam,K., Dinstein,I. (1973) Textural Features for Image Class.

6. Hooke, J.M., Yorke, L. (2011) Channel bar dynamics on multi-decadal timescales in an active meandering river. Earth Surf. Process. Landforms 36, 1910-1928. doi:10.1002.

7. Huang, X., Liu, X., Zhang, L. (2014) A multichannel gray level co-occurrence matrix for multi/hyperspectral image texture representation. Remote Sens. 6, 8424-8445. doi:10.

8. Leckie, D.G., Cloney, E., Jay, C., Paradine, D. (2005) Automated Mapping of Stream Features with High-Resolution Multispectral Imagery: An Example of the Capabilities. Photogramm. Eng. Remote Sens. 71, 145-155. doi:10.14358/PERS.71.2.145

9. Li, N., Frei, M., Altermann, W. (2011)Textural and knowledge-based lithological classification of remote sensing data in Southwestern Prieska sub-basin, Transvaal Supergroup, South Africa. J. African Earth Sci. 60, 237-246. doi:10.1016/j.jafrearsci.2011.

10. Lu, D., Weng, Q. (2007) A survey of image classification methods and techniques for improving classification performance. Int. J. Remote Sens. 28, 823-870. doi:10.1080.

11. McFeeters, S.K. (1996) The use of the Normalized Difference Water Index (NDWI) in the delineation of open water features. Int. J. Remote Sens. 17, 1425-1432. doi:10.1080.

12. Mitra, M., Singh, S. (2015) GIS in Demarcation, Management and Planning of Sand Mining Zone. Int. J. Sci. Eng. Res. 3, 137-143.

13. Mountrakis, G., Im, J., Ogole, C. (2011) Support vector machines in remote sensing: A review. ISPRS J. Photogramm. Remote Sens. 66, 247-259. doi:10.1016/j.isprsjprs.2010.

14. Pathak, V., Dikshit, O. (2010) A new approach for finding an appropriate combination of texture parameters for classification. Geocarto Int. 25, 295-313. doi:10.1080.

15. Planet Team (2017) Planet Application Program Interface: In Space for Life on Earth. San Francisco, CA. https://api.planet.com

16. Ramkumar, M., Kumaraswamy, K., James, R.A., Suresh, M. (2015) Sand Mining, Channel Bar Dynamics and Sediment Textural Properties of the Kaveri River, South India: Implications on Flooding Hazard and Sustainability of the Natural Fluvial System Mu., in: Environmental Management of River Basin Ecosystems. Springer International Publishing Switzerland, pp. 283318. doi:10.1007/978-3-319-13425-3

17. Richards, J. a., Jia, X. (1999) Remote Sensing Digital Image Analysis. Springer Berlin Heidelberg, Berlin, Heidelberg. doi:10.1007/978-3-662-03978-6

18. Rouse, J.W., Hass, R.H., Schell, J.A., Deering, D.W. (1973) Monitoring vegetation systems in the great plains with ERTS. Third Earth Resour. Technol. Satell. Symp. 1, 309-317. doi:citeulike-articleid:12009708

19. Wang, C., Pavlowsky, R.T., Huang, Q., Chang, C. (2016) Channel bar feature extraction for a mining-contaminated river using high-spatial multispectral remote sensing imagery. GIScience Remote Sens. 1603, 15481603.2016.1148229. doi:10.1080/15481603.

20. Zha, Y., Gao, J., Ni, S. (2003) Use of normalized difference built-up index in automatically mapping urban areas from TM imagery. Int. J. Remote Sens. 24, 583-594. doi:10. 